\title{
ENTRE ARMADILHAS E ATALHOS: ACADÊMICOS E ARTISTAS INDÍGENAS NO CONTEXTO INTERÉTNICO DE RORAIMA
}

\author{
João Francisco Kleba Lisboa ${ }^{1}$
}

\section{Introdução}

Quando fui à Roraima com o intuito de realizar minha pesquisa de doutorado entre os acadêmicos indígenas - termo local utilizado para designar tanto os indígenas com diploma de ensino superior quanto aqueles que estão cursando a universidade -, tendo focado o trabalho de campo na Universidade Federal de Roraima (UFRR) e suas relações com os povos indígenas, não demorei a perceber a centralidade que as imagens ocupam naquele contexto interétnico e intercultural. Roraima é o estado mais indígena do Brasil: de acordo com o último censo do IBGE os autodeclarados índios (por volta de 55 mil pessoas) configuram $11 \%$ do total dos habitantes do estado, enquanto no país inteiro esse percentual seria de 0,4\% (IBGE, 2012).

$46 \%$ da área do estado é atualmente reconhecida como território indígena, dividido em pelo menos 34 Terras Indígenas (TIs) regularizadas ou em processo de demarcação. Apenas a TI Raposa Serra do Sol tem mais de um milhão e setecentos mil hectares. Na cidade de Boa Vista, por sua vez, há mais de 9 mil índios morando e muitos outros que por ali passam e ficam temporariamente em busca dos serviços oferecidos ou resolvendo questões burocráticas e outros tipos de problemas. De acordo com o Conselho Indígena de Roraima (CIR), no entanto, a população indígena no estado supera os 60 mil indígenas vivendo nas aldeias e mais 30 mil indígenas vivendo nas cidades, a maior parte em Boa Vista, totalizando 90 mil indivíduos, o que corresponderia a 18\% da população roraimense ${ }^{2}$.

São ao menos nove povos ou etnias indígenas cujos territórios são em parte sobrepostos pelo estado de Roraima, alguns transpondo as fronteiras de outros estados (AM, PA) ou de outros países (Guiana, Venezuela). Dentre eles, os Macuxi, de língua Caribe, e os Wapichana, de língua Aruaque, além de serem os mais populosos, são os dois povos que mais se fazem presentes na capital Boa Vista e nas instituições culturais

\footnotetext{
${ }^{1}$ Universidade Federal do Paraná, Brasil.

${ }^{2}$ Fonte: Folha de Boa Vista, 19/04/2016, disponível em: http://www.folhabv.com.br/noticia/CIR-diz-queEstado-tem-90-mil-indigenas/15679.
} 
e educacionais do estado, assim como tendem a controlar, juntamente com representantes dos Taurepang e Ingaricó, as organizações indígenas supraétnicas, como o já mencionado CIR e a Organização dos Professores Indígenas de Roraima (OPIR). São também conhecidos como os "povos do Lavrado", em contraposição aos povos que habitam ecossistemas de floresta ou o alto das serras ${ }^{3}$.

Em algumas comunidades indígenas, chega-se de carro em menos de uma hora, partindo de Boa Vista, o que reforça a proximidade física e a presença indígena no centro nevrálgico das decisões políticas do estado. Manifestações e mobilizações do movimento indígena e suas organizações na capital, com amplo comparecimento e apoio das comunidades, são frequentes e com pauta diversificada. O histórico de violências a que os indígenas foram submetidos e os conflitos em torno das demarcações mais recentes ainda reverberam na política e na imprensa locais, produzindo discursos e efeitos diretos em quase todo o estado de Roraima.

Algumas pessoas em Boa Vista usam o termo macuxi para se referirem a si mesmas sem serem indígenas, como um sinônimo de quem nasce em Roraima, nos moldes do que já ocorre com potiguar ou carioca. Um estado criado recentemente, junto com a Constituição de 1988, e cujas elites ainda hoje veem os índios como empecilhos ao desenvolvimento, acaba por roubar deles - numa espécie de mais-valia simbólica - as marcas mais importantes de sua própria identidade (a damorida, o caxiri/pajuaru etc). Como escreveu Manuela Carneiro da Cunha (2009: 239), lembrando o famoso texto de Peter Fry "sobre a apropriação nacional da feijoada e do samba", "os símbolos distintivos de grupos, extraídos de uma tradição cultural e que podem servir pra resistência, são frequentemente abocanhados em um discurso oficial”. Roraima não é exceção.

Apesar disso, talvez o "cartão de visitas" entregue a qualquer um que desembarca pela primeira em Boa Vista - assim como Brasília, uma cidade planejada, com largas avenidas e difícil circulação para pedestres - seja a imagem avistada no meio da Praça do Centro Cívico, onde ficam as sedes dos três Poderes estaduais, além da Catedral, Banco

\footnotetext{
${ }^{3}$ Os Yanomami, cuja população se divide entre os estados de Roraima e Amazonas e também a Venezuela, com cerca de 20 mil indivíduos estimados em solo brasileiro (mesmo que tais fronteiras não façam muito sentido em seu território densamente coberto pela floresta), ocupam um lugar antagônico frente aos indígenas do Lavrado tanto na administração pública quanto no movimento indígena organizado. Tal fato fica explícito na divisão do estado em dois Distritos Sanitários Especiais Indígenas (DSEIs): o DSEI-Leste (Lavrado) e o DSEI-Yanomami (Oeste de Roraima e parte do Norte do Amazonas), e na autonomia da Hutukara Associação Yanomami (que representa também os Yekuana, coabitantes da TI Yanomami) frente às organizações indígenas de caráter centralizador e abrangência supra-étnica ou supraterritorial, todos com sede em Boa Vista.
} 
do Brasil e outras edificações intimidadoras e de arquitetura duvidosa. A praça também é conhecida como Praça do Garimpeiro, por causa de um monumento de pedra bem no centro dela que homenageia essa atividade. O garimpo, apesar de não estar mais em seu auge, é uma das mais associadas às invasões e depredação das terras indígenas no estado.

É fácil lembrar, estando ali (ou estando no Eixo Monumental em Brasília), do que disse Lévi-Strauss em Tristes Trópicos a respeito de Goiânia, projetada para ser a capital federal "a partir do nada" e na época um grande canteiro de obras, sem qualquer suspeita de que o destino iria substituí-la por outro local, somente alguns quilômetros a leste e alguns anos depois. Ou então ver a presença ostensiva dos símbolos do poder e o espaço marcado pela distinção entre "povo e autoridades" enquanto uma das chaves para entender (também aquele pedaço) da sociedade brasileira, como apontou Roberto DaMatta. E ainda, pensar nos grandes projetos de interiorização e modernização, que marcaram boa parte dos investimentos públicos e das histórias pessoais de brasileiros no nosso século XX, mais uma vez unindo Boa Vista a Brasília, ambas exaltando a ideia de progresso do País e conquista da "civilização" sobre um ambiente distante ou inóspito: a monumentalidade como promessa de felicidade mas que, traindo seus propósitos, entrega decadência e vaidade, como definiu em sua crítica mordaz Benjamin $\operatorname{Moser}^{4}$ (o que remete a outro Benjamin, Walter: não seria o monumento ao garimpeiro um "documento de barbárie"? ${ }^{5}$ Ou ainda, como propõe Silvia Rivera Cusicanqui (2010), não seria essa estátua elemento para uma "teoria visual do sistema colonial"?).

O presente artigo, extraído em grande parte de minha tese de doutorado em antropologia pela UnB, defendida em 2017, visa ressaltar (e dialogar com) as imagens indígenas contemporâneas que se contrapõem à figura colonial do garimpeiro no meio dos edifícios do poder, constituindo uma espécie de produção visual indígena contracolonial (nos moldes do que Benjamin chamava de "uma história a contrapelo") de si mesmos. A aproximação, ou muitas vezes sobreposição de papeis, entre acadêmicos e artistas indígenas, antes do que planejada, foi algo que despontou no decorrer da própria pesquisa, indicando uma potencialização das agências discursivas quando em contato com múltiplos canais de expressão, desafiando abertamente as linguagens (das artes, da academia) até então exclusivas dos representantes da sociedade colonizadora.

\footnotetext{
${ }^{4}$ Em Cemitério da esperança (Moser, 2014), publicado depois, com alterações, em Moser 2016.

5 Assim escreve Benjamin ([1940] 2013) em suas famosas teses Sobre o conceito da história: "Não há documento de cultura que não seja também documento de barbárie" (p. 13) referindo-se não a uma teoria geral das culturas no sentido antropológico hoje vigente, mas ao processo histórico de avanço da dita "civilização" bem como à soma de despojos - o "cortejo triunfal" - que esse avanço acumula.
} 


\section{Acadêmicos indígenas e as armadilhas das imagens coloniais}

Ao partirem em busca do ensino superior em Boa Vista, os acadêmicos indígenas desenvolvem trajetórias e narrativas que operam vínculos e costuras entre a maloca e a cidade, entre os saberes tradicionais que vivenciam nas comunidades e os saberes científicos que aprendem nos bancos da faculdade, entre diferentes modos de vida, valores, códigos, ambientes e rotinas. Para além de exercerem o papel de mediadores entre ambientes já dados e preconcebidos, no entanto, os acadêmicos indígenas de Roraima, com sua constante produção material e simbólica, duplamente qualificada, contribuem para a construção de tais ambientes e para a disputa de definições a respeito dos mesmos (e de si mesmos).

Juntamente aos vínculos comunitários, étnicos e de parentesco, novas redes e ligações são criadas e alimentadas entre estudantes universitários indígenas de origens e etnias diferentes, que agora se encontram em um contexto urbano e acadêmico e compartilham suas experiências e preocupações, participando da vida universitária e enfrentando dúvidas, dificuldades e preconceitos. Tais reuniões e pontos de encontro, em dinâmica semelhante ao que Magnani e Andrade (2013: 73) já apontavam ao analisar a rotina de indígenas em situação urbana na Amazônia, formariam "pontos de convergência de trajetos e circuitos que atravessam a clássica polaridade aldeia versus cidade”.

A fala a seguir é um excelente exemplo de como os indígenas encaram esses pontos de convergência no papel de sujeitos ativos. Em abril de 2015, no evento da Secretaria do Índio do Estado de Roraima para comemorar a semana dos povos indígenas em torno do dia 19 de abril, Denivaldo Trajano Raposo, que exerce um cargo de confiança na Secretaria, iniciou seu discurso falando na língua macuxi por dois minutos e meio. Depois disso, passou a falar em português. Estudante de matemática na Universidade Estadual de Roraima (UERR) e de Gestão Territorial Indígena na Universidade Federal de Roraima (UFRR), além de professor de língua macuxi e fabricante de arcos e outros utensílios tradicionais, Denivaldo tem uma visão ao mesmo tempo clara e desafiadora sobre a situação que ele e muitos outros indígenas enfrentam na cidade, explicando-a de maneira muito didática para os não-índios presentes, alguns dos quais seus próprios professores, uma vez que o evento era desenvolvido em parceira com a UERR:

É o Dia do Índio, mas aqui em Roraima, aqui na Secretaria do Índio nós estamos todos juntos - brancos, índios e não-índios. Então nós estamos comemorando juntos. No 
forró, quando a gente vai para o forró, os caras não discriminam a gente? "Vai embora daqui, seu índio", ele não diz? Então aqui é nossa festa. Eu estou vendo que tem mais branco do que índio. Por quê? Porque nós estamos na maloca deles. Mas deixa eu contar só uma pequena história aqui, professora. Aqui eu fiz um filme e o nome do meu filme é "Minha Maloca Virou Cidade". Por quê? Tem muitas pessoas que... ainda bem que aqui na Secretaria do Índio não tem nenhum que pensa e nem falou assim: "O que vocês querem aqui na cidade, hein? O que vocês querem na faculdade, na UERR, na Federal?", aí eu respondi, já que essa pessoa me perguntou. Eu respondi assim, professora, "Olha, aqui era a minha maloca, aqui era a maloca indígena. Aqui era a maloca indígena, tinha tuxaua, tinham os Paravianas". Vocês pensam que Paraviana é bairro que os brancos botaram? Não, é nome dos índios Paraviana. Então eles foram dizimados, eles foram empurrados, eles foram no sentido Amazonas. Quem estuda História e Geografia estuda sobre isso, né, professor. Eu faço Gestão Territorial Indígena para nós aprendermos a fazer projeto, nosso território, nossa história, a nossa cidade. Então, é a cidade que veio para a maloca. Os brancos vieram para a maloca, aí foram se estruturando, asfaltos, prédios. Aí vem território federal, vem não sei o que, aí foi crescendo, está crescendo e vai crescer. Vai crescer. Não tem como nós falarmos do índio, não tem como nós falarmos de vocês (falar mal, né), não tem como nós brigarmos [Depoimento público de Denivaldo Trajano Raposo na Secretaria do Índio do Estado de Roraima, 15/04/2015, gravado e cedido por Wellen Araújo].

Como os antigos sábios indígenas demonstraram, dominar as práticas linguísticas e a arte contar histórias é realmente um conhecimento de efeitos poderosos, que requer muito treino, pois é capaz de transformar - ao menos discursivamente - a cidade novamente em maloca, de apropriar-se novamente dela, invertendo a imagem que os brancos têm sobre aquilo que consideravam o "seu" lugar, ou pelo menos turvando uma visão antes segura sobre a cidade. Ao afirmar que "aqui era maloca”, Denivaldo também se utiliza do argumento da anterioridade, tão eficaz no mundo dos brancos para se estabelecer posse e domínio territorial. Num contexto de conflitos interétnicos acirrados como o que existe em Roraima, onde a preponderância da questão da terra já ficou evidente, tal afirmação não é em vão, pois reforça as diversas maneiras de identificar-se com o território (no qual a cidade se encontra). Como notou a antropóloga Luciana Marinho de Melo (2012):

Partindo do entendimento suscitado pelos indígenas que residem em Boa Vista acerca da ocupação territorial, é preponderante o argumento da ancestralidade. Essa compreensão possui respaldo dos relatos transmitidos de uma geração para outra e, mais atualmente, nas pesquisas científicas no âmbito da arqueologia e antropologia. Saliento que esse entendimento ganhou força e foi mais amplamente disseminado a partir das lutas pela terra que teve seu ponto crítico com a homologação da TI Raposa Serra do Sol. Na região que compreende a cidade de Boa Vista, o argumento permanece e é reafirmado através das lideranças da ODIC [Organização dos Índios da Cidade] e acadêmicos indígenas da UFRR (p. 25).

Melo ressalta que, com o ingresso dos Macuxi e Wapichana no ensino superior e a consequente apropriação dos instrumentos do saber acadêmico, eles desenvolvem uma 
"releitura" da presença indígena na cidade, indo muito além da "concepção de que se trata de um fluxo recente motivado por finalidades exclusivamente econômicas" (p. 26), como geralmente a questão é tratada pelos pesquisadores não-índios. Nessa disputa de argumentos e narrativas, em que ferramentas científicas (“arqueologia e antropologia") e tradicionais ("relatos transmitidos de uma geração para outra”) são igualmente requisitadas, outras técnicas somam-se à habilidade com as palavras a que referi acima. O filme "Minha Maloca Virou Cidade", um curta-metragem de menos de três minutos e sem diálogos, em que Denivaldo é o roteirista e ator principal, mostra-o em meio aos carros e prédios públicos do centro de Boa Vista. Na cena final, vê-se o indígena desafiando com seu arco a famigerada estátua do garimpeiro. O que está em jogo é o lugar do índio neste mundo, daí a inversão, a afirmação de que este mundo é o lugar do índio: "esses seres estranhos é que deveriam se explicar, não nós", é o que as imagens parecem dizer. Trata-se, portanto, de uma reindigenização do espaço urbano. De volta à Secretaria do Índio, Denivaldo segue falando:

Então, aí quando eles falam, eu falo desse jeito, “Aqui era a minha maloca”. Então, já que vocês são professores, eu também vou estudar, eu também vou aprender, mas só que falando a minha língua. Eu tomo Pajuaru, mas também eu tomo Coca. Eu como Damorida, mas eu como pizza também. [risos e palmas] Então eu não vivo só de Damorida, entendeu? Hoje eu estava lá estudando, agora eu já estou na faculdade. Não é porque eu sou melhor do que os outros, é porque eu quero o melhor pra mim, para o meu filho. Então, assim como eu falei em Macuxi, assim como os brancos vivem fazendo pesquisa, estudando, investindo, nós também temos que investir em nós. Eu faço flecha, mas eu também faço resenha. Eu faço resumos, eu faço conteúdos. Entendeu? É isso. Então os outros, demais professores... eu sou professor de língua também. Aqui eu nem estou dando aula, eu estou só contando um pouquinho do que eu sou, mas eu nem contei o que eu pretendo ser(...). Então essa comunidade, essa maloca, se desenvolveu tanto que virou capital. Se todos os brancos daqui de Boa Vista ouvissem o que eu estou falando seria legal, eles não falariam mais besteira. “Ah, os índios só estão no lixão!”. Olha, só está lá quem foi pra lá. Eu não estou lá, eu nunca nem fui lá. E não é que eu estou zombando daquele que está lá, não estou não, com todo o respeito [Depoimento público de Denivaldo Trajano Raposo na Secretaria do Índio do Estado de Roraima, 15/04/2015, gravado e cedido por Wellen Araújo].

O desenvolvimento, ideia tão cara aos ocidentais, também é apropriado por essa nova forma de ver a cidade: foi a maloca que "se desenvolveu tanto que virou capital", evidenciando uma agência indígena ancestral e fundadora, da qual a capital é tributária. Em sua fala, Denivaldo foge de armadilhas imagéticas como o lugar folclórico e "museificado" em que alguns discursos pretendem manter os indígenas de Roraima, como verdadeiros fiadores simbólicos a garantir a identidade cultural do estado, sua gastronomia típica, entre outras coisas. Mas também a armadilha da imagem, 
exaustivamente difundida na mídia e conversas locais, do índio pobre, faminto, que está no lixão catando comida, que precisa de ajuda dos brancos, do governo etc. Nesse momento de sua fala, uma senhora indígena que estava na plateia intervém: "não, mas lá tem mais ‘civilizado' do que índio”. Ou seja, isso [estar no lixão] que muitos adversários querem divulgar como sendo a prova do fracasso do modo de ser é, na verdade, o fracasso do mundo dito "civilizado", a miséria das grandes cidades, a indigência, a desigualdade extrema, a produção incontrolada de resíduos.

A identidade de acadêmico indígena passa a atuar como um duplo antídoto contra esses estereótipos, com suas novas ferramentas que, em vez de substituir, agregam-se às técnicas e saberes que esses indígenas trazem consigo. Ela é capaz de refutar tais acusações depreciativas e ao mesmo tempo afirmar as novas potencialidades adquiridas: “eu não fui lá [no lixão]. Se eu for lá, talvez seja para fazer pesquisa”. A coexistência do acadêmico com o guerreiro em uma mesma pessoa produz passagens interessantes como esta, que encerra a fala de Denivaldo na Secretaria:

\begin{abstract}
Por isso que eu estou dizendo, eu nunca fui lá [no lixão], é por isso que eu não posso nem falar, é porque eu não fui lá. Se eu for lá, talvez seja para fazer pesquisa, se eu for lá talvez seja para levar um pão para aquele que está lá. Se ele está lá é porque ele estava mal, não sei! Então não é porque eles vieram da maloca para a cidade, é porque aqui era a maloca deles. Eu não largo a minha flecha. Aqui tinham cinco sargentos e policiais, e eu com a minha faca e a minha flecha eles ficam me olhando. Só que eu nunca flechei ninguém, nem vai ser preciso. Seeeee não for preciso, nunca vai ser flechado por mim, tá bom? Então nós estamos aqui para aprender, para estudar, para se unir, para se entender, assim eu falei macuxi. Você que estão aí pesquisando, trabalhando, fazendo relatórios, nós também somos acadêmicos! Nós também estamos tendo visão para estudar, para reivindicar, para projetar, para coordenar, para governar nas políticas de desenvolvimento. Gestão Territorial fala muito sobre desenvolvimento, muito mesmo. Então eu agradeço aqui desde já a todos vocês que estão aqui, que são bem pouquinho, mas muito obrigado mesmo. Eu estou até orgulhoso porque a UERR está aqui presente e eu também faço parte lá, tá. Muito obrigado por essa oportunidade que me deram. Eu estou ali e que Deus abençoe todos nós - secretários, os convidados, os professores, os visitantes, o que divulgarem no Face e no jornal. Não falem besteira mais, "Os índios...!". Olhem, cuidado [Idem].
\end{abstract}

Se a vida cidade obriga esses acadêmicos a uma constante interpelação dos preconceitos e estereótipos formados sobre a identidade indígena, é contra tais imagens distorcidas que suas narrativas de autoafirmação vão se construindo; é sobre ou a partir desse material (resíduo?) que novas bricolagens vão sendo costuradas, que um discurso ativo a respeito do ser indígena e estar na universidade vai dando forma a um contexto muitas vezes desprezado pela própria antropologia. O alcance teórico dessa disciplina, que muito contribuiu para ajudar a entender a riqueza e as imbricações do pensamento indígena, parece encontrar uma barreira quando adentra as cidades e os contextos 
urbanos. Paradoxalmente, não é isso o que fazem os acadêmicos indígenas, que tomam para si este papel que alguns estudiosos não indígenas preferiram descartar.

\section{Arte indígena contemporânea e universidade: espaços de mediação criativa e intercultural}

Como exemplo da diversidade de elementos e situações que compõem os caminhos dos indígenas entre a sua comunidade e a cidade, passando pela vida acadêmica, optei por destacar e direcionar algumas linhas para a arte indígena contemporânea, seja pela expressividade que ela tem hoje no contexto local de Roraima, seja por oferecer outros idiomas (para além do científico, do mítico, do discurso politizado do movimento indígena) em que se manifestam os desafios vividos por esses indígenas. Mas o meu principal interesse talvez esteja nas próprias histórias de vida desses artistas, dos quais apresento um em particular. O artista indígena do povo Macuxi, Jaider Esbell, disse-me certa vez: "a arte me leva a lugares onde eu demoraria muito mais tempo para chegar se fosse de outra forma", o que me fez concordar, pensando no tempo que eu levaria para desenvolver a pesquisa de doutorado da qual resultou este artigo, por exemplo. No caso de Jaider - que hoje vive de sua arte, e seus quadros e livros tornam-se cada vez mais conhecidos e premiados, tendo sua obra já recebido alguns prêmios em âmbito nacional ${ }^{6}$ - hoje é possível falar assim, mas não houve atalhos em sua vida. Jaider vem de uma família "que foi serviçal nas fazendas" da região de Normandia, e sua ida a Boa Vista foi antes para encontrar trabalho, dando assim condições para os seus planos de ser artista. Quando o entrevistei em sua própria galeria de arte, já nos conhecíamos havia praticamente um ano. O início de seu depoimento chama atenção por ser um misto de história pessoal, genealogia familiar e quadro sociológico interétnico da região da Raposa antes da desintrusão dos fazendeiros:

Então, eu sou Macuxi, eu nasci na região da Raposa Serra do Sol, aliás na região da
Raposa, hoje Raposa Serra do Sol, nas imediações das comunidades Lameiro, Santa
Cruz, Jiboia, Macaco, mas eu nunca estive vinculado diretamente a nenhuma dessas

\footnotetext{
${ }^{6} \mathrm{O}$ último que Jaider recebeu foi o Prêmio PIPA Online de arte contemporânea, no qual concorreu com dezenas de artistas brasileiros, dentre eles outros dois artistas indígenas (um Huni Kuin do Acre e outra Pataxó da Bahia, que ficou em $2^{\circ}$ lugar), e foi escolhido como vencedor por votação na internet, em duas etapas. $\mathrm{O}$ fato de que dois dos meus colegas de doutorado (um do Acre, outra da Bahia) estivessem fazendo campanha para esses outros artistas indígenas, enquanto eu pedia votos para Jaider Esbell, demonstra o quanto esse tipo de interlocutor é valorizado por nós, etnólogos (ver mais em http://www.premiopipa.com/pag/jaider-esbell/).
} 
comunidades. Nós éramos uma família autônoma e eu morei lá na região até os 18 anos, até 1998, quando eu deixo a região para vir para a capital para estudar. Minha família continua morando lá na região e sai da região em 2006. Hoje minha família mora toda fora da Raposa da Serra do Sol e isso faz parte também da dinâmica da minha trajetória, da trajetória de meu povo, mas diretamente da minha família. Eu venho de uma família que foi serviçal nas fazendas. Meu avô foi criado como escravo de fazenda, menino de fazenda, e a partir daí já teve toda uma influência, um reflexo da minha trajetória familiar e inclusive na trajetória do meu trabalho. Então eu nasci nesse interfluxo entre a cidade, a vila de Normandia e as comunidades. Boa parte da minha infância foi dividida entre estar na escola ou estar na vila vendendo alguma coisa da nossa produção para sobreviver, ou estar na comunidade também fazendo essas vivências relacionadas a trocas também comerciais, trocas de alimentos e outros utensílios. E boa parte também da minha vida nessas duas realidades tem a ver com a questão de a gente ter contato com as fazendas. Eu fui menino vaqueiro também muito cedo, lidei com gado. E para lidar com gado você tem que estar aonde o gado está, no caso em toda a região. Então eu tive contato com as comunidades e também com a vila [Entrevista com Jaider Esbell realizada em 20/03/2016 na Galeria Jaider Esbell de Arte Contemporânea].

A experiência como "menino vaqueiro" e a lembrança da exploração nas fazendas por si só já seriam suficientes para justificar a procura de melhores condições longe dali. Mas a ida para a cidade, neste caso, ainda teria outras motivações, de natureza profunda. Em sua narrativa da vinda para a cidade, o curso universitário aparece bem mais tarde, e ocupando um papel secundário na trajetória de Jaider Esbell. O curso é citado tanto em função de garantir uma estrutura/condição para poder exercer seu projeto pessoal, quanto em função da "curiosidade de ser artista" - para a qual o conhecimento do mundo (literalmente) oferecido pelo curso de Geografia deveria ajudar. Mas é a arte a protagonista do relato, formando um caminho paralelo (alternativo para muitos, principal para Jaider) de formação individual:

Em 2001, já trabalhando, eu entrei na faculdade. Fiz faculdade de Geografia por uma questão de disponibilidade de curso mesmo. Gostaria de ter sido/tentei ser engenheiro florestal, engenheiro civil, quis ser dentista, quis ser jornalista. E depois eu fiz Geografia por tentar entender o mundo de uma forma mais ampla, baseada nessa curiosidade de ser artista, de ser escritor, então foi o curso que me foi mais atrativo nessa perspectiva. Trabalhando, eu fiz minha graduação em 2007 também. Depois fiz pós-graduação em Meio Ambiente e Desenvolvimento Sustentável, tentei mestrado, mas não tive êxito. Foi quando em 2010, na época que eu ganhei o prêmio de literatura da Funarte, Prêmio Funarte de Criação Literária, edição 2010, foi quando eu começo a materializar esse desejo da infância que era me tornar um contador de histórias, um artista, que seja. Trabalhar alguma coisa nesse sentido da arte. Então 2010 é um marco na minha trajetória quando eu recebo esse prêmio e começo, a partir daí, a exercer a função de artista, escritor, enfim.

(...) A minha vida toda foi preenchida pelo desenho e pela literatura, pela produção de textos. Só que na época não tive como guardar esse material. O primeiro prêmio, que eu me lembre, de arte, foi no Congresso de Catequistas Indígenas aqui na região dos Wapichana, no Canauanim. Eu devia ter uns 14 anos e eu lembro que fiz um desenho e fui premiado com uma panela de barro. Depois desse tempo eu foquei nos estudos e não pratiquei arte com tanta intensidade. Todo o projeto da minha vida foi baseado nessa busca de conseguir uma estrutura para poder me exercer artisticamente. Vir para 
a capital, procurar um trabalho, fazer uma faculdade foi sempre planejando conseguir uma condição de exercer a minha habilidade artística [Idem].

A fala de Jaider é um exemplo explícito de como o caminho traçado entre a maloca e a cidade não é uma linha reta, pois conta com muitas curvas, interrupções, desvios e encruzilhadas. Os ambientes de formação do jovem indígena misturam-se, conectam-se, projetam-se. A arte, portanto, aparece como mais um meio possível de, eu não diria formação, mas revelação de si e do mundo, o que no caso de Jaider pareceu ser um processo simultâneo.

Quando ele fala que sua "vida toda foi preenchida pelo desenho e pela literatura"7 é isso que dá a entender: Jaider preenche as telas e as páginas, enquanto estas o preenchem: composição mútua, agências múltiplas, double twist, ou melhor, "lápis de duas pontas". Não a linearidade da vida comum, do trabalho científico, mas os mergulhos torcidos e implicantes da expressão artística; não a universidade, mas a vivência:

Não fui para a universidade de artes, então meu trabalho é a expressão de toda a minha vivência. Eu sempre acredito que a arte é feita através de um lápis que tem duas pontas: a ponta do presente que fixa no presente, e a ponta de trás que se fixa no passado. Sou Macuxi, os Macuxi moram no Brasil, Venezuela e Guiana, antigamente Guiana Inglesa, hoje só Guiana. Nossa realidade, assim como as demais realidades ameríndias, é muito complexa, muito rica, rica de diversidade e de comunicação (Esbell, 2014: 254).

As obras de Jaider Esbell, que já percorreram alguns salões pelo Brasil afora e fora dele, hoje encontram-se espalhadas por vários ambientes urbanos, com exposições de seus quadros e painéis em lugares de destaque na cidade (Assembleia Legislativa, Universidade, Shoppings, Centros culturais), além de decorarem casas e consultórios de admiradores particulares.

Não se trata, portanto, daquilo que James Clifford (1994) aborda quando escreve sobre a apropriação ocidental de objetos tribais em museus e coleções etnográficas, ou em como esses "artefatos culturais" (categoria científica) podem ser promovidos a "obras

\footnotetext{
${ }^{7} \mathrm{O}$ fato de Jaider ser simultaneamente escritor e pintor, além de outras atividades que exerce, por si só já desafia a noção ocidental de que essas duas artes estariam separadas, segundo Tim Ingold (2011), "em polos opostos de uma dicotomia entre imagem e texto" (p. 177, em tradução aproximada minha). Tanto o artista quanto o teórico vão contra essa definição e, a meu ver, é possível encontrar afinidades surpreendentes na prática e na explicação de um e do outro: “À medida que fazem coisas, os praticantes ligam seus próprios caminhos ou linhas de devir à textura do mundo. É uma questão não de impor forma à material, como no assim chamado modelo hilemórfico de criação, mas de intervir nos campos de força e fluxos do material em que as formas das coisas surgem e sustentam-se. Portanto a criatividade do fazer reside na prática ela mesma, em um movimento de improvisação que trabalha as coisas à medida que as acompanha" (p. 178, idem).
} 
de arte" (categoria estética), numa análise muito mais voltada para uma "história crítica do colecionar" do que para as novas noções, nativas e estrangeiras, do que seja arte indígena e de como essa arte está inserida no campo de relações sociais indígenas e interétnicas.

Acredito que iniciativas como a exposição MIRA! Artes Visuais Contemporâneas dos Povos Indígenas, na Universidade Federal de Minas Gerais (UFMG), coordenada por Maria Inês de Almeida, da qual Jaider Esbell participou, distanciam-se da abordagem de Clifford e aproximam-se mais desta última (ver, por exemplo, Dinato, 2014).

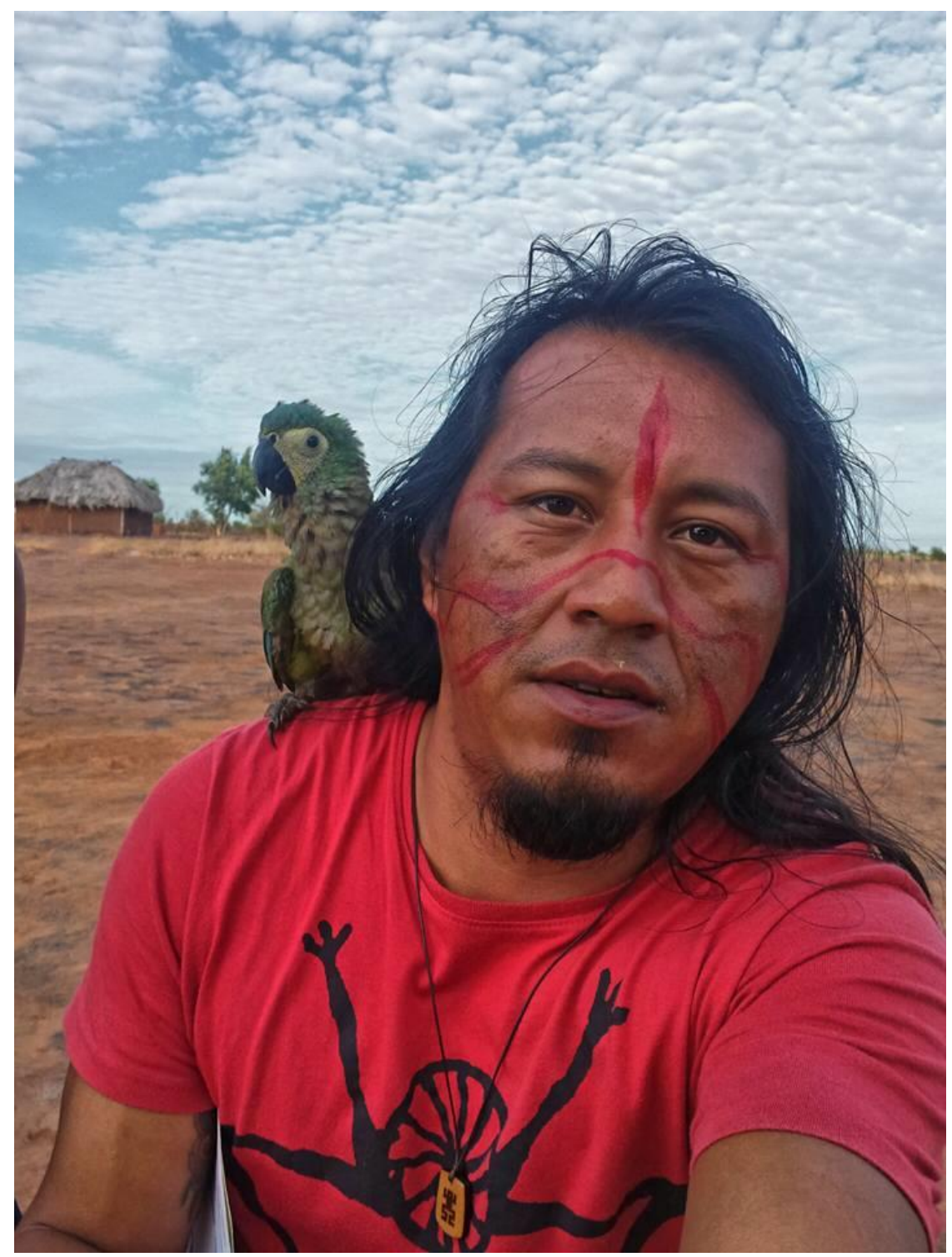

Figura 1: Jaider Esbell (Foto cedida por Jaider Esbell, 2016) 
Jaider também organiza ou colabora com eventos culturais em Boa Vista e nas comunidades indígenas, sempre com ênfase nas culturas indígenas do estado e nos diálogos interculturais. Como exemplos de trabalho junto às comunidades, Jaider colabora com Enoque Raposo na organização do Anna Komanto' Eseru - Festival da Panela de Barro, na comunidade da Raposa I, e tem projetos de arte com o povo Xirixana da comunidade Sikamabiu, na TI Yanomami. Dentre as diversas atividades realizadas por Jaider em que pude participar na cidade, destaco o III Encontro de Todos os Povos $^{8}$, no Espaço de Arte e Cultura União Operária, que aconteceu paralelamente à II Semana dos Povos Indígenas, organizada em janeiro de 2016 pelo Instituto Insikiran na UFRR; e também o Festival das Culturas Nativas ${ }^{9}$ que aconteceu em sua própria Galeria Jaider Esbell de Arte Indígena Contemporânea, no bairro do Caçari/Paraviana, em dezembro do ano anterior. Nesses eventos, Jaider é um grande divulgador do trabalho de outros artistas e artesãos indígenas, alguns bem mais velhos do que ele, ao mesmo tempo em que exerce o papel de um mediador intercultural ou interétnico entre povos indígenas e não-índios algo semelhante ao que fazia trabalhando na Eletrobrás, porém agora muito mais à vontade, sem a imposição hierárquica da estrutura empresarial.

Enoque Raposo, indígena Macuxi formado em Secretariado Executivo pela UFRR, não é pintor nem escritor, mas está diretamente envolvido com a Galeria Jaider Esbell, de que toma conta quando Jaider viaja. Enoque divide seu tempo entre Boa Vista e sua comunidade, Raposa I, próxima à sede do município de Normandia, desenvolvendo estudos e projetos que visam a implementar propostas autônomas e equilibradas de divulgação - através do turismo, por exemplo, ou dos eventos culturais, que organiza com Jaider e outros "entusiastas" indígenas - das belezas naturais e culturais da TIRSS. Enoque é um grande conhecedor da Terra Indígena em que vive, tendo-a percorrido diversas vezes. Mantém contato também com o outro lado da fronteira, na Venezuela, e já subiu o Monte Roraima uma dezena de vezes. Suas publicações no Facebook são

\footnotetext{
${ }^{8}$ Assim Jaider Esbell descreveu o Encontro para um jornal local: "O projeto reúne artistas, artesãos e mestres dos saberes ancestrais para socializar a cultura de seus povos por meio da arte tradicional e contemporânea. Queremos iniciar uma discussão crítica de assuntos de interesse local/global, com temas que abordem sustentabilidade ecológica, diversidade sociocultural e diálogo entre povos e nações na busca de um entendimento comum" (Fonte: http://www.folhabv.com.br/noticia/III-Econtro-de-Todos-os-Povos/13233).

${ }^{9}$ Ver, por exemplo, o site de notícias http://www.folhabv.com.br/noticia/Festival-das-Culturas-Nativasacontece-esta-semana-em-Boa-Vista/12183.
} 
verdadeiras aulas ${ }^{10}$ sobre a cultura de seu povo e sobre a região, ilustradas por fotos belíssimas que ele mesmo registra nas suas andanças.

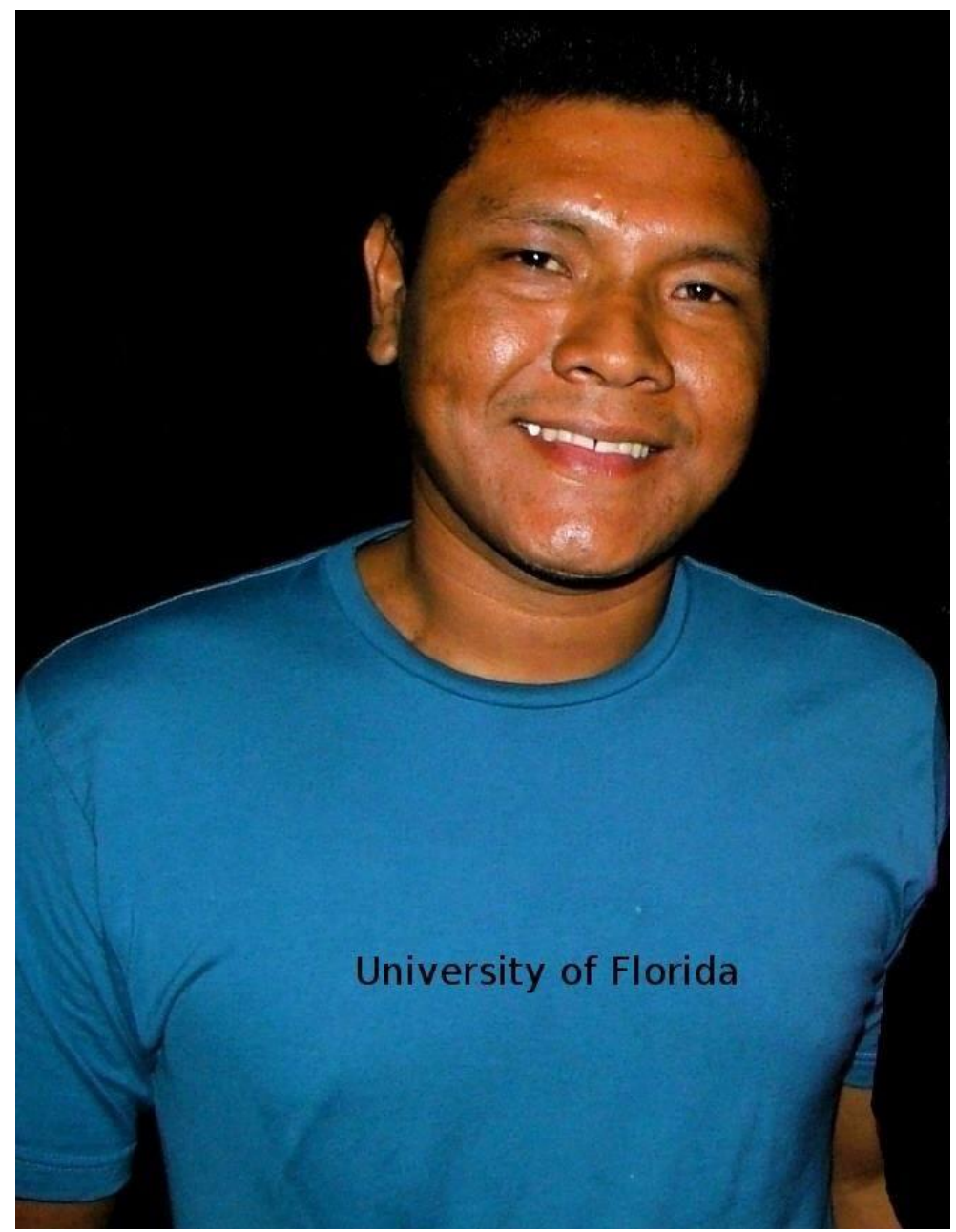

Figura 2: Enoque Raposo (Foto cedida por Enoque Raposo)

Enoque Raposo é filho do Sr. Caetano Raposo - um antigo e reconhecido líder indígena da comunidade da Raposa, que infelizmente faleceu durante a minha pesquisa e também é, por assim dizer, um guardião dos conhecimentos indígenas de sua região, tendo me contado diversas histórias sobre episódios e seres que, para a ciência ocidental, seriam descritos como "sobrenaturais", mas que são muito comuns e aparecem constantemente nos relatos desses percursos pelo território indígena - seja em expedições de caça e pesca, seja nas roças ou nos trajetos entre as comunidades, "pelo mato".

10 Ver, por exemplo, a publicação em que Enoque explica a História da Damurida (https://www.facebook.com/enoque.raposo/posts/1281278055252198). 
Dentre as explicações que recebo, fico sabendo que existe uma série de cuidados que o indígena deve ter antes de sair de casa, para que não seja alvo dos seres maléficos, protegendo-se assim das "malinagens" que estes aprontam. Mostrou-me também um artigo que escreveu com mais dois colegas (não-índios) da UFRR, ainda não publicado, onde registram a memória oral da formação da comunidade da Raposa I pelos Macuxi, num processo de "deslocamento das famílias da região das serras para o Lavrado, em meados do século XX”. No artigo, recheado de ricos depoimentos, os autores mapeiam as sete famílias fundadoras da comunidade, que desceram das serras em busca de melhores condições. Enoque já morou nos Estados Unidos, onde fez um curso de especialização na University of Florida, e guarda contatos pessoais e amizades desse período. Atualmente, exerce muito daquilo que as comunidades esperam de um acadêmico indígena, compondo uma espécie de corpo intelectual renovado da comunidade e atuando como um mediador entre o mundo indígena e alguns setores do mundo dos brancos.

O meio universitário, dessa forma, surge quase naturalmente como um lugar propício para exercer esse diálogo, como um ambiente impulsionador do encontro entre diferentes formas de expressão e conhecimento. É onde Enoque encontrou parceiros de pesquisa e de projetos. E é onde Jaider encontrou espaço para desenvolver e expor o seu trabalho. Mas a Universidade também permite a eles interagirem com estudantes e profissionais de diversas áreas e titulações, como interlocutores valorizados, na qualidade de conhecedores e ao mesmo tempo de representantes da cultura indígena.

Remetendo ao que Jaider falou acima, penso que nesses casos a arte seja uma forma em que os saberes e práticas indígenas encontrem menos resistência (e, portanto, cheguem mais rápido) no meio acadêmico, seja pela linguagem mais "aberta a interpretações", seja pelo atrativo da beleza física que alguns painéis oferecem, ou apenas por proporcionarem uma desejada representatividade das culturas locais que existem ao redor (ou seja, fora) daquele ambiente.

A presença da arte e de grafismos indígenas nos prédios do campus da UFRR, se não é hegemônica, vai muito além do malocãozinho no centro do bloco composto pelo Instituto Insikiran, estando presente em murais e fachadas e compondo a decoração interna do Restaurante Universitário, um dos ambientes mais frequentados da Universidade. Essas imagens passam despercebidas por muita gente, e há mesmo quem não goste delas. Mas comete um grave engano quem acha que a forma artística é 
inofensiva ou meramente decorativa, esquecendo-se dos saberes ancestrais que ela carrega consigo, da capacidade poderosa que a arte tem de produzir efeitos ${ }^{11}$ e de transfigurar-se em outros formatos e discursos, transpondo barreiras disciplinares.

No seguinte trecho da entrevista, falamos sobre isto, e Jaider pôde relatar um pouco de sua vasta experiência com algumas universidades, inclusive fora do País:

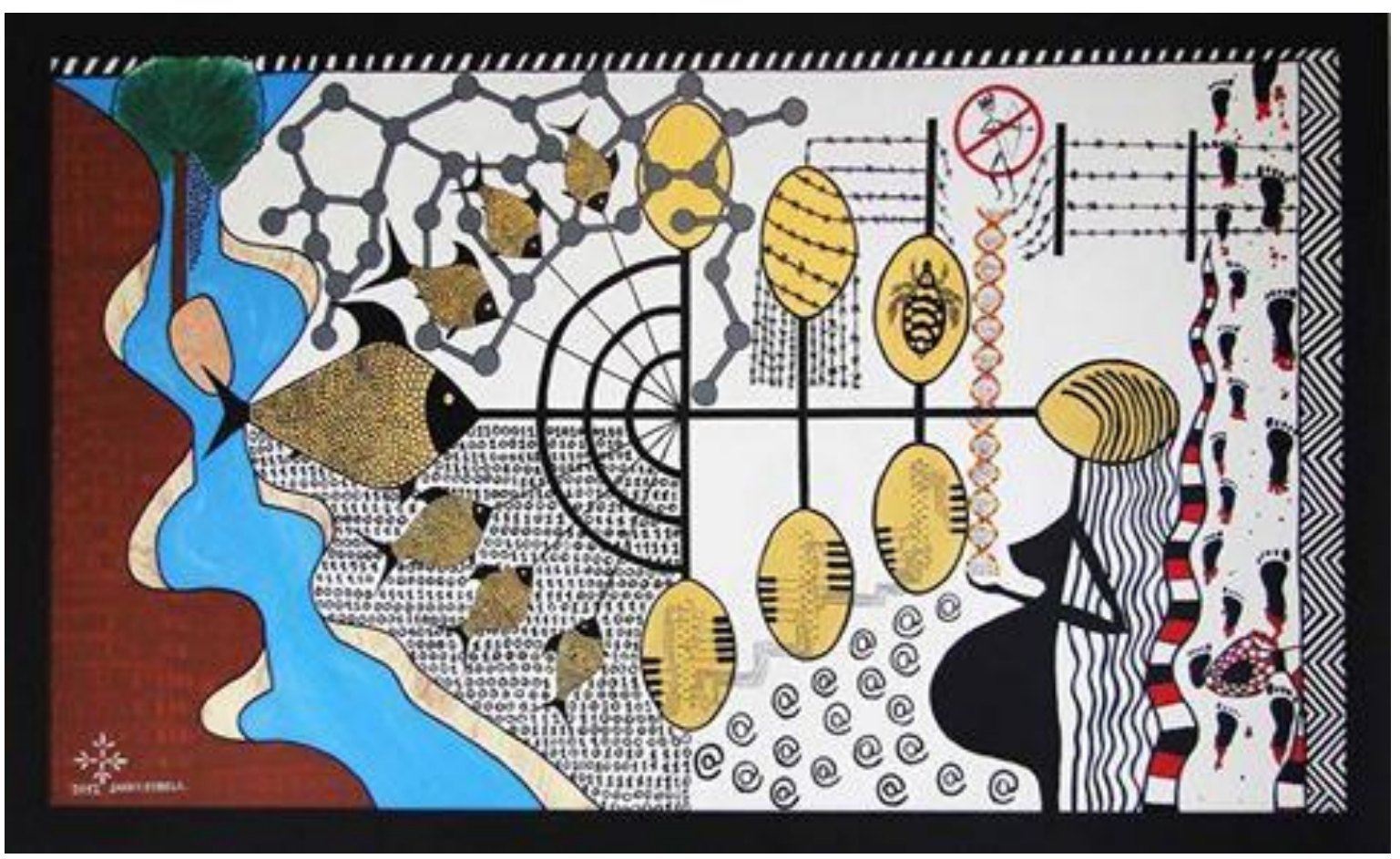

Figura 3: Dignidade e Conhecimento. 160 x 250cm. Jaider Esbell, 2012.

(Foto cedida por Jaider Esbell)

Jaider: O Painel Dignidade e Conhecimento é um pouco disso: trazer essa observação de que antes da própria ciência existir, existe o conhecimento milenar, ancestral, espiritual. E eu acredito que os povos indígenas, para ter a dignidade que tanto querem, passam por essa questão de esse conhecimento ser reconhecido dignamente. Isso leva para questões de estudar outros modelos de certificar esses conhecimentos, que a própria academia não compreende. Hoje o meu trabalho está em várias universidades. Eu tenho um trabalho com a Universidade de Santa Maria também,

\footnotetext{
${ }^{11}$ De acordo com Els Lagrou (2007), a partir dos escritos de Alfred Gell sobre a eficácia ritual de uma proa de canoa trobriandesa, "a decoração não se quer bonita, mas poderosa, visa a uma eficácia, a uma agência, a uma produção de resultados práticos em vez de contemplação. A maestria decorativa cativa e terrifica os que olham, param e pensam sobre os poderes mágicos de quem produziu e possui tal canoa" (p. 43). Essa eficácia potencial, afirmam Gell e Lagrou, seria uma qualidade tanto de objetos rituais de povos tribais quanto daquilo que nós ocidentais chamamos de "obras de arte". Em outro texto, Lagrou (2010) reforça tal característica comum: “A obra de arte, portanto, não serve somente para ser contemplada na pura beleza e harmonia das suas formas, ela age sobre as pessoas, produzindo reações cognitivas diversas. Se fôssemos comparar as artes produzidas pelos indígenas com as obras conceituais dos artistas contemporâneos, encontraríamos muito mais semelhanças do que à primeira vista suspeitaríamos[...]. São objetos que condensam ações, relações, emoções e sentidos, porque é através dos artefatos que as pessoas agem, se relacionam, se produzem e existem no mundo" (p. 2).
} 
envolvendo a memória do povo Macuxi, uma colaboração para o Memorial da Neusa Carson, que foi uma pesquisadora linguista que passou aqui na época que eu era criança, três/dois anos, ela passou pesquisando os índios. 30 anos depois o meu trabalho é visto, percebido e é convidado para compor essa memória, de um trabalho de uma pesquisadora, baseado na memória do povo que ela pesquisou. A Universidade Federal de Minas Gerais tem muito material meu divulgado também, inclusive obras de arte e publicações. E são vários pesquisadores de várias universidades, inclusive de outros países, que têm trabalhos iniciados com a pesquisa, com a linguagem da minha arte, da minha comunicação, de modo que estar fazendo parte mais diretamente agora desse campo de conhecimento, de pesquisa da universidade é realmente uma satisfação [Entrevista com Jaider Esbell realizada em 20/03/2016 na Galeria Jaider Esbell de Arte Contemporânea].

É evidente que o contato com as instituições de ensino superior não está livre de mal-entendidos, frustrações e surpresas, o que é próprio de aproximações desse gênero e integra qualquer processo de conhecimento mútuo. E não apenas por parte dos estudantes norte-americanos na Califórnia. No livro que Jaider Esbell publicou com professores da Universidade Federal de Santa Maria (UFSM) em homenagem à pesquisadora Neusa Carson, chamou minha atenção justamente esse choque de expectativas produzido pela primeira tentativa de contato entre os pesquisadores gaúchos e o artista indígena roraimense, como se pode ler na Apresentação escrita pela Profa. Dra. Simone de Mello de Oliveira (2014):

eis que Jaider Esbell Makuxi responde que está nos Estados Unidos, que está escrevendo de seu smartphone, mas que quando chegar em casa pode conversar melhor, por meio de seu computador, mas desde já confirma que pode ajudar. Nossa surpresa foi grande porque todo o nosso imaginário, dos índios nas ocas, isolados, caiu por terra. Percebemos que os indígenas da atualidade estão conectados, via computador e smartphone, que eles são artistas plásticos, estudantes e estão completamente inseridos no mundo globalizado (p. 10).

Jaider Esbell não é o único artista indígena de Roraima a fazer sucesso no Brasil e no exterior. Amazoner Okaba, indígena Wapichana da Malacacheta, conta como já expôs em Paris, na Alemanha e nos EUA. O Vaticano adquiriu uma "coleção exclusiva" de obras suas e outras foram compradas pelos presidentes Lula e Dilma. Ao ser perguntado por uma jornalista se "tinha noção de que seu trabalho ganharia o mundo", respondeu assim: "Eu queria conquistar a minha maloca, não imaginei que poderia atingir vários países". Amazoner Okaba é graduado em Antropologia pela UFRR e mestre em Antropologia pela UFPE. Em outro trecho do seu Perfil, publicado por Shirley Rodrigues (jornalista e colunista social que apoia e dá amplo espaço em sua coluna aos artistas indígenas como Jaider Esbell, Amazoner Okaba, Carmézia Emiliano, Bartô, entre outros), o assunto, como é quase inevitável quando se tratam de indígenas como ele (além de 
artista, um acadêmico), passa a ser a Universidade e o acesso de indígenas a esse meio até então restrito a eles:

Pergunta: Você entrou na Universidade pelo sistema de cotas?

AO: Não, entrei pelo sistema tradicional. Tive mais acesso, estudei em escolas públicas e depois no antigo Cefet-RR e, posteriormente, na UFRR onde cursei a graduação e pós-graduação em Etnodesenvolvimento. Depois fiz o mestrado em antropologia social na UFPE sem acessar cotas e bolsa. Banquei todo meu mestrado com recursos próprios. Embora existisse uma bolsa da Fundação Ford em dólar quem acessou essa bolsa foi um amigo de mestrado, Tukano do Alto Rio Negro. Sem essa bolsa ele dificilmente conseguiria fazer o mestrado. A consciência social sempre fala em primeiro lugar. Eu não tiraria a vaga e a oportunidade de uma pessoa com menos acesso do que eu.

Pergunta: Que sugestão você daria para garantir o acesso de indígenas que moram nas comunidades à universidade pelo sistema de cotas?

AO: Deve-se intensificar o diálogo entre as instituições no nível informativo, organizacional e investigativo. Sabemos que, após a desintrusão da Terra Indígena Raposa Serra do Sol, inúmeras pessoas sem nenhuma ligação sociocultural, territorial, identitária, hereditária ou de ethos correram para tirar o Rani [Registro de Nascimento Indígena] buscando a possibilidade de acessar uma vaga nas universidades e atrás das bolsas. Refiro-me aos não-índios (brancos karaiwa), muitos deles anti-indígenas, que agora acham interessante, senão oportuno, serem índios para acessar um ethos, status étnico que não é seu.

Pergunta: Mensagem:

AO: Maloca, Makunaima, serras, lavrado, parixara, damurida, taren, Kanaime, caxiri, buriti, lendas, mitos, rituais tudo representa nossa cultura milenar, nossa civilização das fibras de nosso povo, Aruak e Karib, nossa identidade amazônida caribenha roraimense (Folha de Boa Vista, 30 e 31 de janeiro de 2016, p. 09).

O trecho acima da entrevista que Amazoner Okaba concedeu ao jornal local mostra como a questão do acesso de indígenas ao ensino superior é ainda fonte de muitas controvérsias (e inclusive tentativas de apropriação desonesta das políticas de acesso e bolsa por parte de não-índios). Também é uma mostra de como a passagem pelo meio acadêmico deixou a sua marca na vida do entrevistado, com a aquisição de um status para usar o termo que Okaba empregou, porém em outro sentido - diferenciado (graduado, especialista, mestre) e o domínio de algumas das ferramentas conceituais e teóricas das ciências sociais. Mas o trajeto pelas diversas instituições de ensino superior, entre problemas gerais que persistem e ganhos pessoais adquiridos, é antes de tudo mais uma forma de contar a própria história, ressaltando características individuais e étnicas, demonstrando como certos valores são mantidos, entre eles a "consciência social", a ajuda ao amigo, o engajamento. Assim como Jaider Esbell causou espanto nos pesquisadores gaúchos por ser um “índio globalizado”, Amazoner Okaba é um indígena Wapichana que fala com propriedade sobre ethos e status, é mestre em antropologia e, ao mesmo tempo, desfia os principais elementos da sua "cultura milenar", de sua identidade “amazônida/caribenha/roraimense". 
O fato de ambos serem artistas indígenas contemporâneos pode indicar que ocupam uma posição especial, semelhante à de porta-vozes e intérpretes das suas respectivas culturas, como operadores relevantes de uma mediação interétnica criativa e intercultural. Nessa condição, ter passado pela universidade e continuar mantendo contato com ambientes acadêmicos potencializa o alcance da representatividade que exercem (nos dois sentidos), ajudando a criar e consolidar verdadeiros espaços de mediação criativa entre saberes e técnicas, culturas e identidades.

Lukas Van Diermen, um jovem pesquisador holandês que pude conhecer pessoalmente em Boa Vista ao final de minha pesquisa de campo - quando ele acabava de chegar para a sua - no início de 2016, também aponta para esse papel de negociadores operado pelos artistas indígenas. Em sua pesquisa de mestrado, Van Diermen (2016) reflete sobre como os artistas indígenas contemporâneos de Boa Vista, agindo coletivamente, "negociam as fronteiras entre índios e não-índios no espaço urbano", retratando a galeria de Jaider Esbell como um lugar central e agregador nesse processo.

Tanto a presença desses artistas no contexto urbano quanto a apropriação que fazem da noção e da forma ocidental de arte, afirma Van Diermen, são maneiras de contestar tentativas simplistas de definir o que é ou não é indígena ${ }^{12}$. Além de desafiarem as "fronteiras da indianidade", buscando reverter o peso da marginalização sobre os indígenas no espaço urbano, ou sua invisibilidade, Van Diermen identifica outros temas predominantes nas produções desses artistas, como a crítica social voltada para o mundo dos brancos, e o retrato da solidariedade/comunidade dos povos indígenas.

Clifford Geertz (2009) já havia refutado a ideia comum que pressupõe uma diferença irredutível nos papeis e dinâmicas exercidos pela arte nas sociedades complexas e nos povos ditos "sem escrita", ideia baseada na visão contrastante de que, nestes, a arte seria algo que se dissolveria e se fundiria no todo da experiência coletiva, enquanto naquelas ela formaria um domínio especializado e autônomo de atividade.

Geertz, ao contrário, propõe ver a arte, tanto num caso como em outro, nem como apreciação estética autônoma e insular, nem como sinônimo metonímico da cultura, mas

\footnotetext{
${ }^{12}$ Assim Lukas Van Diermen descreve a galeria de Jaider Esbell: "é também um lugar urbano onde artistas vinculados a comunidades rurais reúnem-se em um esforço para chamar a atenção do público para seu trabalho. A simples presença de artistas indígenas em um contexto urbano, assim como a apropriação que fazem da abordagem ocidental tradicional sobre o lugar da arte na sociedade, é uma contestação de noções simplistas do que é e não é indígena. Sobretudo, suas perspectivas sobre o mundo, muitas vezes politicamente carregadas, encontram vazão na temática do seu trabalho" (Diermen, 2016: 13, em tradução livre minha).
} 
algo que se desenvolve numa relação interativa com esta. Geertz afasta-se também de uma explicação funcionalista da arte como algo que define ou fortalece relações sociais. Em vez disso, ressalta as influências mútuas, em que arte e vida social refletem os conceitos uma da outra, partilhando "formas simbólicas" e "sensibilidades":

A conexão central entre a arte e a vida coletiva, no entanto, não se encontra neste tipo de plano instrumental e sim em um plano semiótico. A não ser muito indiretamente, os rabiscos coloridos de Matisse (em suas próprias palavras) e as composições de linhas dos ioruba não celebram uma estrutura social nem pregam doutrinas úteis. Apenas materializam uma forma de viver, e trazem um modelo específico de pensar para o mundo dos objetos, tornando-o visível (p. 150).

A relação tensa e algo ressentida entre antropologia e arte ingressou o centro de algumas das principais questões teóricas da disciplina antropológica, dada a visão privilegiada por meio da qual a arte permite pensar as relações mantidas entre pessoas e coisas (artefatos, imagens, objetos em geral). Essa parece ser a abordagem utilizada por alguns dos principais representantes da antropologia social britânica atual, como Alfred Gell (1998) e Marilyn Strathern (2014) - focados nas relações sociais e, portanto, na ação e nos efeitos produzidos, em contraposição a uma abordagem "culturalista", mais interessada no sentido e que, como escreveu Lagrou (2007: 42), vai "buscar inspiração em outras disciplinas tais como a estética, a semiótica e a linguística, a história da arte ou a crítica literária". A noção de Geertz acima citada é claramente um exemplo deste segundo tipo de abordagem. Sem querer ingressar e muito menos encontrar solução para essa querela entre as diferentes escolas teóricas, reconheço que ambas desenvolvem conceitos úteis para o caso aqui brevemente explorado, uma vez que tanto a ação quanto o sentido são elementos reivindicados pelos artistas e agentes indígenas aqui mencionados.

Além disso, a arte visual indígena vem sendo objeto de um frutífero debate no Brasil, destacando-se o livro de Lux Vidal (1992) sobre grafismo indígena e os trabalhos de Els Lagrou aqui já mencionados. A discussão sobre o uso de objetos e danças rituais indígenas em contextos interétnicos, como em manifestações políticas, ou para produção de distintividade cultural, já foi levantada por Manuela Carneiro da Cunha (2009), entre outros autores. Mas pouco se tem falado ou escrito sobre a arte indígena contemporânea e seus praticantes, o que a meu ver é uma grande lacuna tanto para o debate antropológico quanto para o reconhecimento do cenário atual das sociedades indígenas inseridas em relações interétnicas. 
Tais relações oferecem novos temas e motivos para esses artistas, assim como renovam a importância dos elementos tradicionais de suas culturas, fazendo com que se tornem agentes de uma interlocução profunda e abrangente entre formas, métodos e saberes.

\section{Considerações finais}

Observando-se o contexto interétnico de Roraima, percebe-se de forma explícita o quanto os sinais da identidade indígena estão em constante transformação e disputa, sempre ameaçados de serem engolidos ou manipulados por discursos oficiais e pelos estereótipos que marcam aquela região do país. Procurei aqui, com base nas falas de acadêmicos e artistas indígenas, sobretudo do povo Macuxi, e que transitam entre os diversos tipos de espaços e linguagens de expressão, enfatizar o contra-discurso que estes sujeitos constroem frente a tais ameaças de natureza colonial.

A produção de imagens, seja com filmes, pinturas, painéis, fotos publicadas em redes sociais, mas também com metáforas, trocadilhos, histórias, anedotas, remete às tradições ancestrais revividas no ato de contar histórias, de narrar os mitos, de cantar as melodias épicas e cosmogônicas dos povos indígenas.

A arte contemporânea indígena, assim como a produção intelectual e a inserção de acadêmicos indígenas dentro de espaços definidos como "culturais" nos centros urbanos, passa a ser cada vez mais uma forma de expressão indígena inovadora, mas que nem sempre chama atenção dos estudiosos da antropologia ou das artes. Contudo, ambas constituem hoje uma parte importante da agencialidade indígena em Roraima, sobretudo no que se refere ao controle sobre as imagens criadas em torno de si mesmos. Daí a ênfase no contraste com as imagens representativas do poder colonial: a estátua do garimpeiro, por um lado, mas por outro a tentativa de fixar o índio folclórico, de divulgar o índio miserável como o oposto de uma sociedade que se desenvolve. Mais do que uma arte militante ou uma ciência engajada, contudo, o que essas pessoas produzem são imagens alternativas, inesperadas, surpreendentemente autônomas em relação às formas oficiais ou acadêmicas de expressão/valoração. 


\section{REFERÊNCIAS}

ANDRADE, José. A. A. D.; Magnani, José Guilherme C. Uma experiência de etnologia urbana: a presença indígena em cidades da Amazônia. In: AMOROSO, Marta Rosa; SANTOS, Gilton Mendes dos (Org.). Paisagens Ameríndias: Lugares, circuitos e modos de vida na Amazônia. 1ed. São Paulo: Ed. Terceiro Nome, 2013, p. 45-74.

BENJAMIN, Walter [1940]. Sobre o conceito da história. In BENJAMIN, Walter. O anjo da história ; organização e tradução João Barrento. - $2^{\mathrm{a}}$ ed. - Belo Horizonte: Autêntica, 2013 (Filô/Benjamin).

CLIFFORD, James. Colecionando arte e cultura. In: Revista do Patrimônio Histórico e Artístico Nacional, n. 23, p. 69-89, 1994.

CUNHA, Manuela Carneiro da. Cultura com aspas e outros ensaios. São Paulo: Cosac Naify, 2009.

CUSICANQUI, Silvia Rivera. Ch'ixinakax utxiwa: una reflexión sobre prácticas y discursos descolonizadores. Buenos Aires: Tinta Limón, 2010.

DINATO, Daniel Revillion. Permanências e mudanças na arte indígena: o caso da exposição "Mira!". Monografia (graduação) Universidade Federal do Rio Grande do Sul - Curso de Ciências Sociais. Porto Alegre, 2014, 46 páginas.

ESBELL, Jaider. Eu sonho em ter um grande caminhão para colocar todo mundo dentro e passar um mês numa aldeia, um mês na outra, para construir essa cultura coletiva. Mundo Amazônico, 5: 253-259, 2014.

GEERTZ, Clifford. A arte como um sistema cultural. In GEERTZ, Clifford. O saber local: novos ensaios em antropologia interpretativa; tradução de Vera Mello Joscelyne. 11 ed. Petrópolis, RJ: Vozes, 2009.

GELL, Alfred. Art and agency: towards a new anthropological theory. Oxford: Clarendon, 1998.

INGOLD, Tim. Being alive: essays on movement, knowledge and description. New York: Routledge, 2011.

LAGROU, Els. A fluidez da forma: arte, alteridade e agência em uma sociedade amazônica (Kaxinawa, Acre). Rio de Janeiro: TopBooks, 2007.

Arte ou artefato? Agência e significado nas artes indígenas. Revista Proa, $\mathrm{n}^{\circ} 02$, vol.01, 2010.

MELO, Luciana Marinho de. Fluxos Culturais e os Povos da Cidade: Entre os Macuxi e Wapichana de Boa Vista - Roraima. Dissertação de mestrado profissional em 
Preservação do Patrimônio Cultural. Instituto do Patrimônio Histórico e Artístico Nacional. Rio de Janeiro, 2012.

MOSER, Benjamin. Cemitério da esperança; tradução Eduardo Heck de Sá. Recife: Cesárea, 2014.

Cemitério da esperança Brasília aos 50. In Autoimperialismo: três ensaios sobre o Brasil; tradução Eduardo Heck de Sá. - 1ª ed. - São Paulo: Planeta, 2016.

OLIVEIRA, Simone de Mello de. (Apresentação) Da organização da exposição "Neusa Carson: língua e memória" e do arquivo (in)disponível. In ESBELL, Jaider. Memória e Cultura Makuxi [recurso eletrônico] Por Jaider Esbell ; Simone Oliveira, Verli Petri (orgs.). Santa Maria, RS : Laboratório Corpus/PPGL/UFSM, 2014.

STRATHERN, Marilyn. O efeito etnográfico e outros ensaios ; coordenação editorial Florencia Ferrari ; tradução Iracema Dulley, Jamille Pinheiro e Luísa Valentini. São Paulo: Cosac Naify, 2014.

VAN DIERMEN, Lukas. Redrawing the boundaries of indigeneity: how Roraima's indigenous artists negotiate the boundaries between the indigenous and the nonindigenous in an urban setting. Master of arts in conflict studies \& human rights. Utrecht University. 22 august 2016.

VIDAL, Lux (Org). [1992] Grafismo indígena: estudos de antropologia estética. São Paulo: Studio Nobel, 2007. 


\section{Sites consultados:}

http://www.folhabv.com.br/noticia/CIR-diz-que-Estado-tem-90-mil-indigenas/15679 (Matéria publicada em 19/04/2016, acessada pela última vez em 25/04/2018).

http://www.premiopipa.com/pag/jaider-esbell/ (acessado pela última vez em 25/04/2018).

http://www.folhabv.com.br/noticia/III-Econtro-de-Todos-os-Povos-/13233 $\quad$ (acessado pela última vez em 25/04/2018).

http://www.folhabv.com.br/noticia/Festival-das-Culturas-Nativas-acontece-estasemana-em-Boa-Vista/12183 (acessado pela última vez em 25/04/2018).

(https://www.facebook.com/enoque.raposo/posts/1281278055252198 (acessado pela última vez em 25/04/2018). 